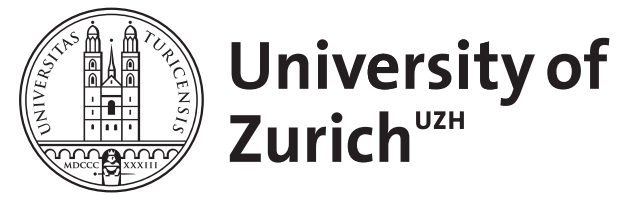

Zurich Open Repository and Archive

University of Zurich

University Library

Strickhofstrasse 39

CH-8057 Zurich

www.zora.uzh.ch

Year: 2021

\title{
Single incision for oncologic breast conserving surgery and sentinel node biopsy - another de-escalation strategy in breast surgery
}

Nguyen-Sträuli, Bich Doan ; Vorburger, Denise ; Dedes, Konstantin J

Posted at the Zurich Open Repository and Archive, University of Zurich

ZORA URL: https://doi.org/10.5167/uzh-214047

Journal Article

Published Version

Originally published at:

Nguyen-Sträuli, Bich Doan; Vorburger, Denise; Dedes, Konstantin J (2021). Single incision for oncologic breast conserving surgery and sentinel node biopsy - another de-escalation strategy in breast surgery. Senologie:33-35. 


\section{Single incision for oncologic breast conserving surgery and sentinel node biopsy- another de-escalation strategy in breast surgery?}

Breast-conserving therapy (BCT) has become the standard of care for the vast majority of patients with early breast cancer [1]. A regular approach are two independent incisions for the breast tumor and the sentinel lymph node (SLN). Despite preserving oncological safety, breast surgery has become progressively less radical in favor of improved cosmetic outcome and minimal functional deficiency over time [2]. Oncoplastic breast conserving surgery (OPS) has been widely promoted to achieve improvements in aesthetic outcome [3, 4].

Recently, minimal access breast surgery (MABS) using a single incision for lumpectomy and SLN retrieval has been promoted by several authors, hereby using a lateral, radial, periareolar, inframammary, and semi- circular incision [5-9]. For access to the axilla, a prepectoral dissection to the lateral edge of the pectoralis major muscle is performed, hereby, entering the clavipectoral fascia for SLN retrieval. Several authors performed lumpectomy with local remodeling (level I OPS according to Clough's classification [10]) using the lateral, axillary, inframammary, or periareolar approach. AceaNebril and colleagues performed level II OPS, namely reduction mammoplasty (wise pattern), horizontal mammoplasty (batwing) and the round block technique ("Donut" or Binelli) with the intent to minimize local complications as axillary neuralgia and lymphoedema [6]. Success rates varied between 90-100\% for SLN retrieval along with comparable complication and re-op- eration rates, but yet, with a tendency to a more frequent formation of seroma in the single incision cohort in one study [6]. Moreover, Acea-Nebril et al. described an improved quality of life and satisfaction using the Breast- $Q^{T M}$ questionnaire along with a lower incidence of axillary neuralgia, less surgical time, and smaller resected tumor volume [6]. Up to this point, patient-reported outcomes and randomized controlled trials (RCT) comparing single-incision vs. two independent incisions are lacking.

To the best of our knowledge, indications for MABS are mostly limited to lateral and central tumors in the current literature ( $\downarrow$ Table 1). However, it remains unclear how to manage tumors farthermost from the axillary region. The round block tech-
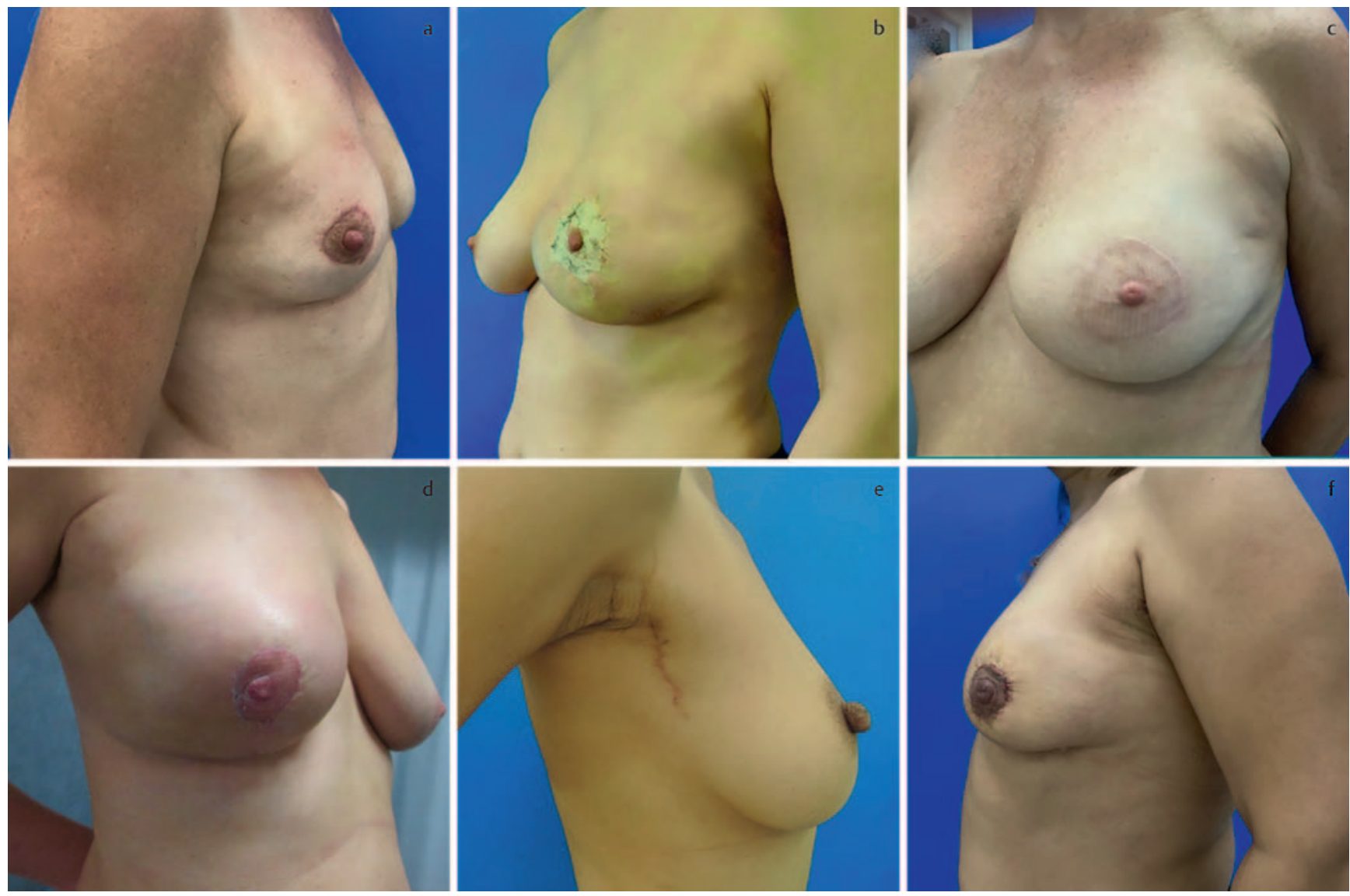

- Fig. 1 Single-incision approaches for breast conserving therapy and SLN retrieval. a 52-year old patient with breast cancer pT1b pN0 (0/2; sn) operated through round block incision, b 46-year old patient with breast cancer ypTis ypN0 (0/4; sn) after round block incision, c 53 -year old patient with breast cancer ypT1a ypNx with periareolar incision, $\mathbf{d}$ 51-year old patient with breast cancer pT3 pN0 (0/1; sn) and round block incision, e 49-year old patient with breast cancer pT1b pN0 (0/2; sn) with lateral incision, f 45 -year-old patient with breast cancer pT2 pN1mi (1/1; sn) and round block incision; SLN: sentinel lymph node. 


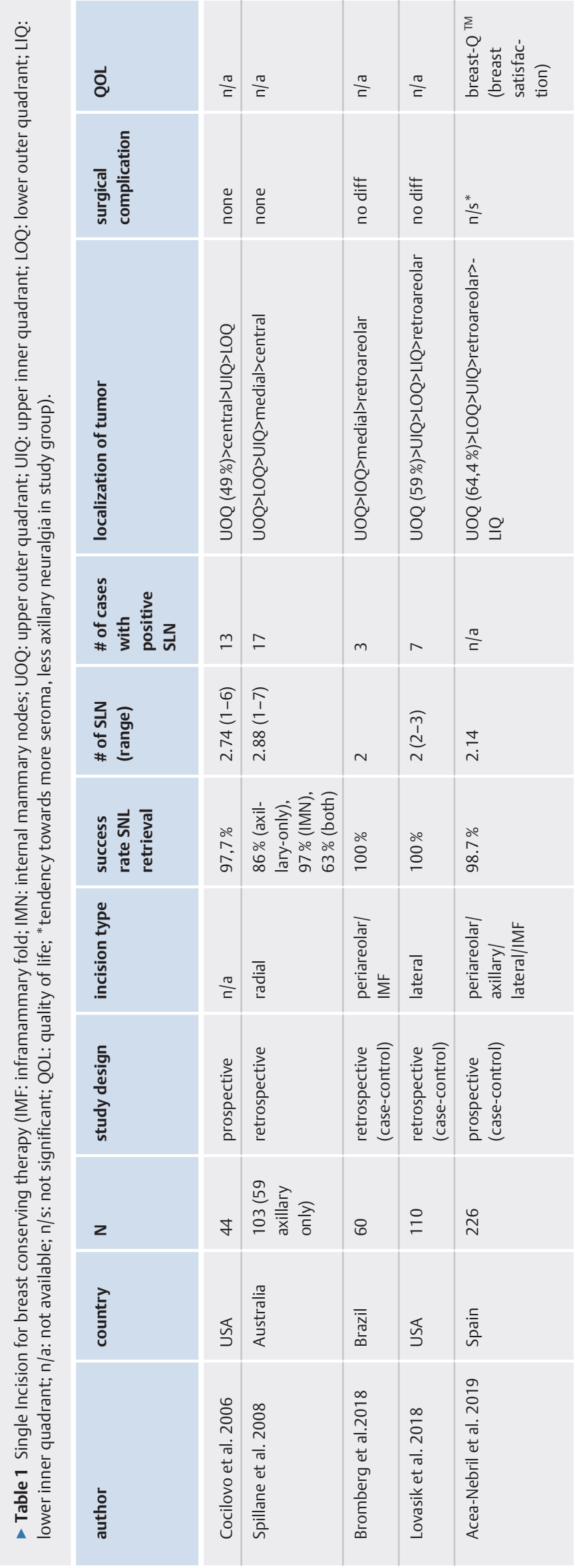

nique as a single incision approach might meet the requirements of the above-mentioned tumor localization ( $\triangleright$ Fig. 1). AceaNebril et al. described level-II-oncoplastic procedures for multifocal and multicentric breast tumors, but only included four patients with round block technique.

Currently, we aim to prospectively analyze patient-reported outcomes and quality of life in a larger cohort after single incision round-block OPS.

\section{Conflict of Interest}

The authors declare that they have no conflict of interest.

Authors

Bich Doan Nguyen-Sträuli, Denise Vorburger, Konstantin Johannes Dedes

Department of Gynecology, Comprehensive Cancer Center, Breast Cancer Unit, University Hospital of Zurich, Switzerland

\section{Correspondence}

PD Dr. med. Konstantin Johannes Dedes Department of Gynecology University Hospital Zurich Frauenklinikstrasse 10 8091 CH-Zürich

Schweiz

konstantin.dedes@usz.ch

References

[1] Veronesi U, Cascinelli N, Mariani L et al. Twenty-Year Follow-up of a Randomized Study Comparing Breast-Conserving Surgery with Radical Mastectomy for Early Breast Cancer. New England Journal of Medicine 2002; 347 (16): 1227-1232. doi:10.1056/NEJMoa020989

[2] Veronesi U, Banfi A, Salvadori B et al. Breast conservation is the treatment of choice in small breast cancer: Long-term results of a randomized trial. European Journal of Cancer and Clinical Oncology 1990. doi:10.1016/0277-5379(90)90113-8

[3] Weber WP, Soysal SD, Fulco I et al. Standardization of oncoplastic breast conserving surgery. European Journal of Surgical Oncology 2017; 43 (7). doi:10.1016/j. ejso.2017.01.006

[4] Weber WP, Soysal SD, Zeindler J et al. Current standards in oncoplastic breast conserving surgery. Breast 2017; 34: doi:10.1016/ j.breast.2017.06.033 
[5] Spillane A], Brennan ME. Minimal access breast surgery - A single breast incision for breast conservation surgery and sentinel lymph node biopsy. European Journal of Surgical Oncology 2009. doi:10.1016/ j.ejso.2008.07.009

[6] Acea-Nebril B, García-Novoa A, CereijoGarea $C$ et al. Single-Incision Approach for Breast-Conserving Surgery: Effectiveness, Complications and Quality of Life. Annals of Surgical Oncology 2019. doi:10.1245/ s10434-019-07443-3

[7] Lovasik BP, Seidel RL, Novello M et al. Single incision for oncologic breast conserving surgery and sentinel node biopsy in early stage breast cancer: A minimally invasive approach. The Breast Journal 2019; 25 (1): 41-46. doi:10.1111/tbj.13158

[8] Bromberg SE, Giordano R. Prime Incision and Modified Moving Window: A Minimally Invasive Access for Breast Cancer Surgical Treatment. World journal of plastic surgery 2016; 5 (3): 252-258

[9] Cocilovo C, Boolbol SK, Valdes E et al. Less is more: transmammary axillary lymph node evaluation: an initial clinical experience. American Journal of Surgery 2006. doi:10.1016/j.amjsurg.2006.06.025

[10] Clough KB, Kaufman G], Nos C et al. Improving breast cancer surgery: A classification and quadrant per quadrant atlas for oncoplastic surgery. Annals of Surgical Oncology 2010. doi:10.1245/s10434-009-0792-y

Bibliography

Senologie 2021; 18: 33-35

DOI $10.1055 / \mathrm{a}-1367-3823$

ISSN 1611-6453

(C) 2021. Thieme. All rights reserved.

Georg Thieme Verlag KG, Rüdigerstraße 14 70469 Stuttgart, Germany 